\title{
HUBUNGAN PENGETAHUAN IBU TENTANG STIMULASI PERKEMBANGAN DENGAN PERKEMBANGAN MOTORIK KASAR ANAK USIA 3-5 TAHUN DI KELURAHANSEI SIKAMBING B KECAMATAN MEDANSUNGGAL
}

\author{
Yulia Safitri*) \\ Surel: fatli_pi2t@yahoo.com
}

\begin{abstract}
The purpose of this study was to identify the relationship of mother's knowledge about developmental stimulation with gross motor development of children aged 3-5 years in the Village Sei Sikambing B district of Medan Sunggal. The results show there is a close relationship between mother's knowledge about developmental stimulation with gross motor development of children aged 3-5 years in the Village Sei Sikambing B Sunggal Medan District, where P value $=0.00(P<0.01)$ from the analysis also shows the correlation $(r)$ of 0.63 . It is suggested to mothers in order to dig deeper information from sources that are accurate about the importance and how to stimulate gross motor development of children.
\end{abstract}

Keywords: Knowledge Mother, Development

\section{PENDAHULUAN}

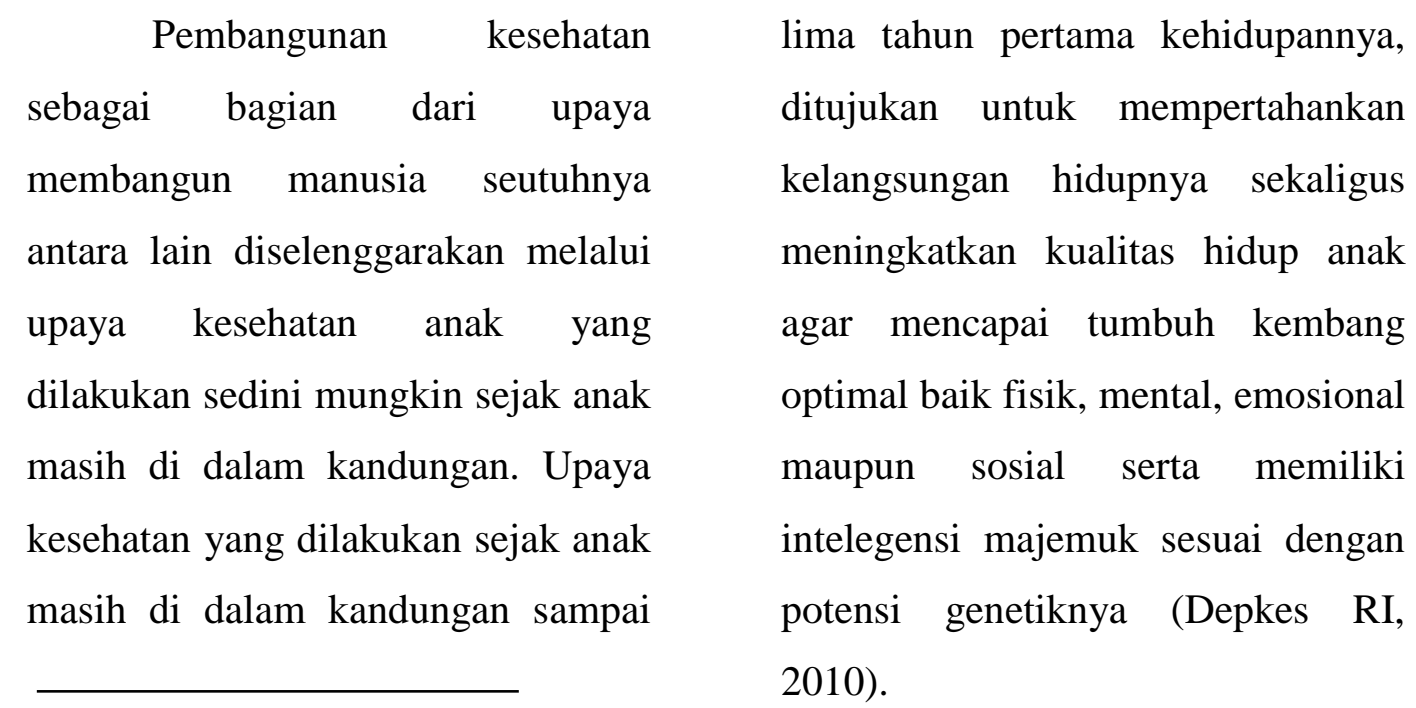

*) Yulia Syafitr, S.ST., M.Kes. Dosen STIKes Flora Medan 
Menurut UNICEF, dari 200 juta anak di bawah usia 5 tahun di Negara -negara berkembang di dunia, lebih dari sepertiganya tidak terpenuhi potensinya untuk perkembangan, di Indonesia sendiri, pada tahun 2003 Departemen Kesehatan RI melakukan skrining perkembangan di 30 provinsi di Indonesia dan dilaporkan $45,12 \%$ anak mengalami gangguan perkembangan. Selain itu, di Jawa Barat hampir 30\% anak mengalami keterlambatan perkembangan dan sekitar $80 \%$ diantaranya disebabkan oleh kurangnya stimulasi (Fadlyana, 2004 dalam Cristi, 2013).

Pada tahun 2007, sekitar $35.4 \%$ anak balita di Indonesia menderita penyimpangan perkembangan seperti penyimpangan dalam motorik kasar, motorik halus, serta penyimpangan mental emosional (Soedjatmiko, 2008 dalam Sunarsih, 2010).

Berdasarkan hasil pelayanan Stimulasi Deteksi dan Intervensi Dini Tumbuh Kembang (SDIDTK) pada 500 anak dari lima Wilayah DKI Jakarta, ditemukan, 57 anak $(11,9 \%)$ mengalami kelainan tumbuh kembang. Kelainan tumbuh kembang yang paling banyak yaitu delayed development (pertumbuhan yang terlambat) 22 anak, kemudian 14 anak mengalami global delayed development, 10 anak gizi kurang, 7 anak Microcephali, dan 7 anak yang tidak mengalami kenaikan berat badan dalam beberapa bulan terakhir (Depkes, 2010).

Apakah ada hubungan antara pengetahuan ibu yang memiliki anak usia 3-5 tahun tentang stimulasi perkembangan dengan perkembangan motorik kasar anak usia 3-5 tahun di Kelurahan Sei Sikambing B Kecamatan Medan Sunggal.

Tujuan penelitian ini adalah ntuk mengidentifikasi hubungan antara pengetahuan ibu tentang stimulasi perkembangan dengan perkembangan motorik kasar anak usia 3-5 tahun di Kelurahan Sei Sikambing B Kecamatan Medan Sunggal.

\section{METODE PENELITIAN}

Dalam penelitian ini peneliti menggunakan metode penelitian kuantitatif. Desain yang digunakan dalam penelitian ini adalah Deskriptif Korelatif dengan 
pendekatan Cross Sectional dimana pengukuran atau pengamatan dilakukan pada saat bersamaan (Point Time Approach) (Notoadmodjo, 2010).

Populasi dalam penelitian ini adalah seluruh ibu yang mempunyai anak usia 3-5 tahun di Kelurahan Sei Sikambing B Kecamatan Medan Sunggal. Jumlah populasi dalam penelitian ini adalah 1300 orang. Sampel dalam penelitian ini adalah ibu yang mempunyai anak usia 3-5 tahun di Kelurahan Sei Sikambing B Kecamatan Medan Sunggal. Dalam penelitian ini besar sampel dihitung menurut rumus (Setiadi, 2011), jadi jumlah sampel yang digunakan dalam penelitian ini adalah sebanyak 93 orang. Dalam penelitian ini teknik sampling yang digunakan adalah Purposive Sampling. Alasan memilih Purposive Sampling adalah karena sampel dalam penelitian ini melakukan teknik penentuan sampel dengan pertimbangan tertentu.

Analisa data yang digunakan dalam penelitian ini adalah

Analisa Univariat (2) Analisis Bivariat yaitu untuk mengetahui hubungan antara variabel independen dan variabel dependen yaitu hubungan penetahuan ibu tentang stimulasi perkembangan dengan perkembangan motorik kasar anak usia 3-5 tahun di Kelurahan Sei Sikambing B Kecamatan Medan Sunggal. Tekhnik analisa yang dilakukan yaitu teknik korelasi Spearman Rank (Rho). Uji Spearman Rank (Rho) ini digunakan untuk mengukur eratnya hubungan antara dua variabel yang berskala Ordinal (Hidayat, 2007).

\section{HASIL DAN PEMBAHASAN}

\section{Analisi Univariat}

Identitas responden meliputi usia umur, agama, suku, pendidikan terakhir, pekerjaan, penghasilan rumah tangga, jenis kelamin anak, usia anak, pengetahuan ibu dan perkembangan motorik kasar anak terdapat dalam tabel berikut :

\section{Tabel 1 Distribusi Responden Menurut Karakteristik.}

\begin{tabular}{llcc}
\hline No & Karakteristik & n & \% \\
\hline 1 & Umur & & \\
\hline & $25-36$ Thn & 27 & 29.0 \\
& & & 3
\end{tabular}




\begin{tabular}{|c|c|c|c|}
\hline \multicolumn{2}{|c|}{$36-45$ Thn } & 52 & $\begin{array}{c}55.9 \\
1\end{array}$ \\
\hline \multirow{2}{*}{\multicolumn{2}{|c|}{ > 46 Tahun }} & 14 & 15.0 \\
\hline & & & 5 \\
\hline \multicolumn{4}{|c|}{2 Agama } \\
\hline \multirow{2}{*}{\multicolumn{2}{|c|}{ Islam }} & 52 & 55.9 \\
\hline & & & 1 \\
\hline \multirow{2}{*}{\multicolumn{2}{|c|}{ Nasrani }} & 41 & 44.0 \\
\hline & & & 9 \\
\hline \multicolumn{4}{|c|}{$3 \quad$ Suku } \\
\hline \multirow{2}{*}{\multicolumn{2}{|c|}{ Jawa }} & 53 & 56.9 \\
\hline & & & 8 \\
\hline \multirow{2}{*}{\multicolumn{2}{|c|}{ Aceh }} & 19 & 20.4 \\
\hline & & & 3 \\
\hline \multirow{2}{*}{\multicolumn{2}{|c|}{ Batak }} & 21 & 22.5 \\
\hline & & & 8 \\
\hline
\end{tabular}

4 Pendidikan

SMP/Sederajat $\quad 15 \quad 16.1$

3

SMA/Sederajat $\quad 50 \quad 53.7$

6

\begin{tabular}{llcc}
\hline & Diploma/S1 & 28 & 30.1 \\
& & 1 \\
& & \\
\hline 5 & Pekerjaan & &
\end{tabular}

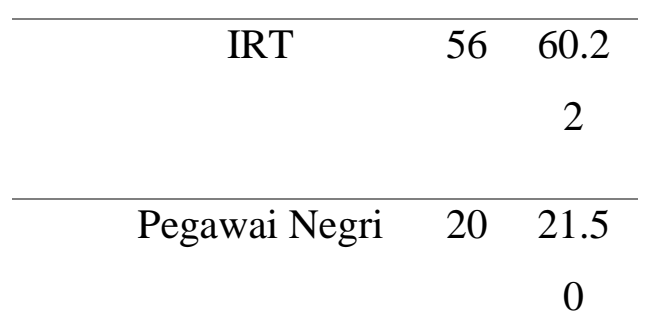

Pegawai Swasta $12 \quad 12.9$

0

Wiraswasta $\quad 5 \quad 5.38$

6 Penghasilan

<Rp. $1.950 .000 \quad 43 \quad 46.2$

4

Rp. 1.950 .000 - $32 \quad 34.4$

Rp. 2.950 .000

$>2.950 .000 \quad 18 \quad 19.3$

5

7 Jenis Kelamin

Anak

Laki-laki

$41 \quad 44.0$

9

perempuan

$52 \quad 55.9$

1

8 Usia Anak

3 Tahun

$27 \quad 29.0$

3

$\begin{array}{lll}4 \text { Tahun } \quad 32 & 34.4\end{array}$ 


\begin{tabular}{lcc}
\hline 5 Tahun & 34 & 36.5 \\
& & 6 \\
& & \\
\hline
\end{tabular}

Berdasarkan tabel di atas dapat diketahui bahwa didapatkan sebagian besar responden berada pada usia 36 - 45 thn sebanyak 52 orang (55.91\%), sebagian besar suku responden adalah suku Jawa sebanyak 53 orang $(56.98 \%)$, sebagian besar responden beragama Islam sebanyak 52 orang $(55.91 \%)$, pendidikan responden sebagian besar adalah SMA yaitu 50 orang $(53.76 \%)$, sebagian besar responden bekerja sebagai ibu rumah tangga yaitu 56 orang $(60.22 \%)$, sebagian besar responden berpenghasilan < Rp. 1.950.000 yaitu sebanyak 43 (46.24\%), sebagian besar anak responden berjenis kelamin perempuan yaitu 52 orang $(55,91 \%)$ dan sebagian besar usia anak 5 tahun sebanyak 34 orang $(36,56 \%)$.

Tabel 2 Distribusi Data Menurut Pengetahuan Ibu dan Perkembangan Motorik Kasar Anak di Kelurahan Sei Sikambing B Medan

\section{Sunggal}

\begin{tabular}{cccc}
\hline No & Karakteristik & n & \% \\
\hline 1 & Pengetahuan Ibu & & \\
& & & \\
\hline & Baik & 3 & 33.3 \\
& 1 & 3 \\
& & \\
\hline & & 4 & 45.1 \\
& 2 & 6 \\
& & \\
& Kurang & 2 & 21.5 \\
& 0 & 0
\end{tabular}

\section{Perkembangan Motorik Kasar \\ Anak}

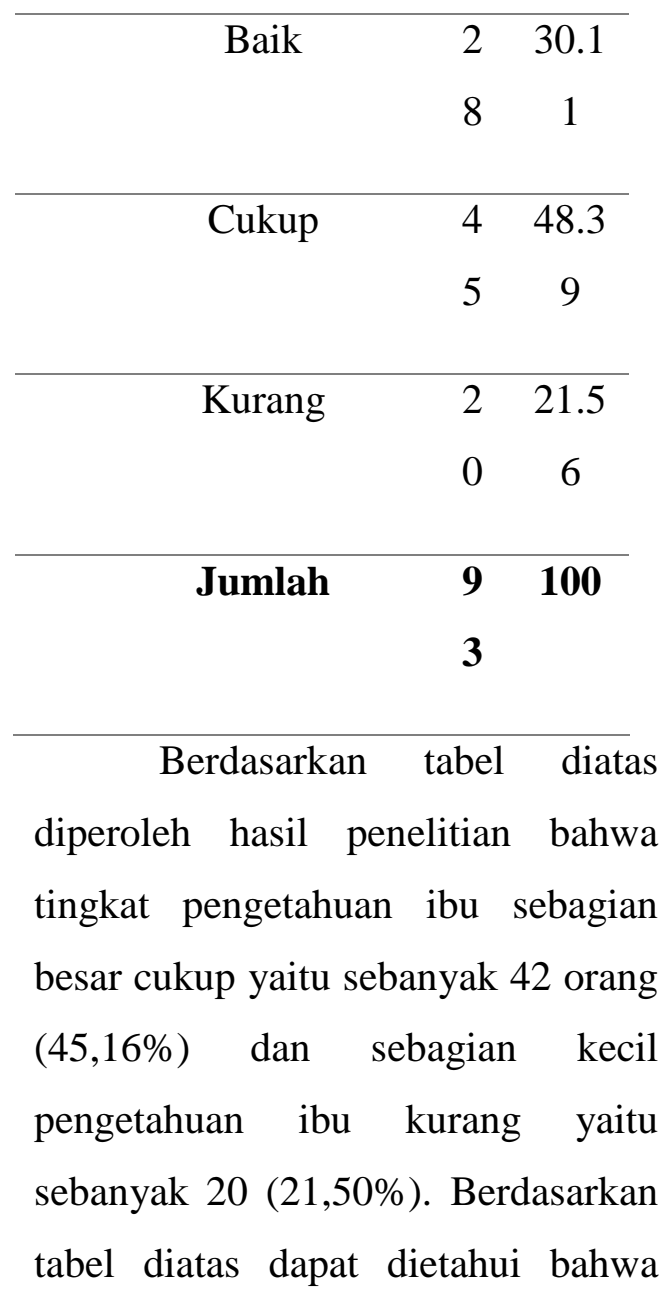


sebagian besar perkembangan motorik kasar anak dengan kategori cukup sebanyak 45 orang (48.39\%),

\section{Analisa Bivariat}

Tabel 3 Hasil Analisis Korelasi Spearman Rho

\section{Correlations}

\begin{tabular}{|c|c|c|c|c|}
\hline & & & Pengetahuan Ibu & $\begin{array}{l}\text { Perkembangan } \\
\text { Motorik Kasar }\end{array}$ \\
\hline $\begin{array}{l}\text { Spearman' } \\
\text { s rho }\end{array}$ & Pengetahuan Ibu & $\begin{array}{l}\text { Correlation } \\
\text { Coefficient } \\
\text { Sig. (2-tailed) } \\
\text { N }\end{array}$ & $\begin{array}{r}1.000 \\
. \\
93\end{array}$ & $\begin{array}{r}.556^{* *} \\
.000 \\
93\end{array}$ \\
\hline & $\begin{array}{l}\text { Perkembangan } \\
\text { Motorik Kasar }\end{array}$ & $\begin{array}{l}\text { Correlation } \\
\text { Coefficient } \\
\text { Sig. (2-tailed) } \\
\text { N }\end{array}$ & $\begin{array}{r}.556^{* *} \\
.000 \\
93\end{array}$ & $\begin{array}{r}1.000 \\
. \\
93\end{array}$ \\
\hline
\end{tabular}

Berdasarkan hasil penelitian dapat dilihat nilai koefisien korelasi antara Pengetahuan ibu tentang stimulasi perkembangan dengan perkembangan motorik kasar anak usia 3-5 tahun di kelurahan sei sikambing B kecamatan medan sunggal adalah sebesar 0,556 dengan taraf signifikan0.000 yaitu $\mathrm{p}$ Value $<\alpha(0,000<0,01)$, maka $\mathrm{H}_{\mathrm{o}}$ ditolak $\mathrm{H}_{\mathrm{a}}$ diterima. Artinya terdapat hubungan positif antara Pengetahuan ibu tentang stimulasi perkembangan dengan perkembangan motorik kasar sebagian kecil kategori kurang sebanyak 20 orang (21.56\%). 
sebagian kecil pengetahuan ibu kurang yaitu sebanyak 20 orang (21,50\%). Hasil penelitian menunjukkan sebagian besar perkembangan motorik kasar anak cukup yaitu sebanyak 45 orang $(48,39)$ perkembangan motorik kasar anak kurang yaitu sebanyak 20 $(21,56 \%)$. Hasil uji statistik dengan menggunakan uji Chi-Square menunjukkan ada hubungan antara pengetahuan ibu dengan perkembangan motorik kasar anak di Kelurahan Sei Sikambing B Medan Sunggal, dimana $\mathrm{P}=0,00(\mathrm{P}<0,05)$ dari hasil analisa juga menunjukkan contingency coefficient 0,59.

\section{Saran}

1. Bagi Pelayanan Keperawatan

Diharapakan menyampaikan kepada keluarga dan masyarakat agar lebih banyak menggali informasi tentang peran dan pentingnya dukungan keluarga dalam perkembagan motorik kasar anak

2. Bagi Pendidikan Keperawatan

Diharapkan menyampaikan informasi lebih dalam dari sumbersumber yang akurat tentang pentingnya dan bagaimana cara menstimulasi perkembangan motorik kasar pada anak.
3. Bagi Peneliti Keperawatan

Diharapakan Kepada paneliti selanjutnya agar dapat menggali informasi lebih jauh tentang hubungan pengetahuan ibu tentang stimulasi perkembangan dengan perkembangan motorik kasar anak, seperti sikap ibu, pengetahuan dan sikap keluarga dan lain-lain.

\section{DAFTAR PUSTAKA}

Christi, A.Y. (2013). Hubungan Pengetahuan Ibu Tentang Stimulasi Dini Dengan Perkembangan Motorik Pada Anak Usia 6-24 Bulan Di Kecamatan Mayang Kabupaten Jember. Diambil tanggal 17 Januari $2014 \quad$ dari http://repository.unej.ac.id/bitstr eam/handle/123456789/1863/A yu\%20Yoniko\%20Christi\%20\% 20\%20092010101001_01.pdf?s equence $=1$

Depkes RI. (2010). 11,9\% Anak yang Mengikuti Sdidtk Mengalami Kelainan Tumbuh Kembang. Diambil tanggal 17 Januari 2014 dari http://www.depkes.go.id/index. $p h p ? v w=2 \& i d=1141$ 
Hidayat, A.A. (2007). Riset Keperawatan dan Teknik Penulisan Ilmiah, Surabaya: Salemba Medika.

Notoadmodjo, Soekidjo. (2010). Metode Penelitian Kesehatan. Jakarta: Rineka Cipta.

Sunarsih, Tri. (2010). Hubungan Antara Pemberian Stimulasi Dini Oleh Ibu Dengan Perkembangam Balita Di Taman Balita Muthia Sido Arum, Sleman Yogyakarta Tahun 201. Diambil tanggal 17 Januari 2014 dari http://ejournal.respati.ac.id/sites/defau lt/files/2012-VI-18TeknologiInformasi/Jurnal\%20 Tri\%20Sunarsih.docx.

Setiadi. (2011). Konsep dan Penulisan Riset Keperawatan. Yogyakarta. Graham Ilmu. 